DOI 10.37882/2223-2982.2020.06.38

\title{
ФРАЗЕОЛОГИЗМЫ СО ЗНАЧЕНИЕМ “НЕОПРЕДЕЛЕННО БОЛЬШОЕ КОЛИЧЕСТВО” В РУССКОМ ЯЗЫКЕ: ПРОБЛЕМА ПОДХОДА К КЛАССИФИКАЦИИ
}

\section{PHRASEOLOGISMS WITH THE MEANING "INDEFINITE LARGE QUANTITY" IN RUSSIAN LANGUAGE: PROBLEMS OF CLASSIFICATION APPROACH}

Zhang Jintao

Summary: The problem of classification of phraseologism with the meaning "an indefinite large quantity" is analyzed in the article. The basis of classification is not the structure of phraseologisms, but their degree of contextual freedom / connectedness. According the opinion of the author, the structural approach, proposed by M.Yu. Tikhonova does not allow to see lexical and semantic nuances in the meanings of $\mathrm{FE}$, which determine the valence bonds of phraseologisms. According to the author, the pragmatic approach proposed in the article, is especially relevant for foreigners. The classification presented in the article includes three groups of FE: contextually free, contextually limited, contextually related. FE of the first group are combined with nouns of different lexical and semantic categories and act as synonyms in relation to each other. The valence bonds of FE of the second group are limited tither by additional components of meaning associated with the internal form of phraseology, or by its polysemy or structure. In the meanings of phraseological units of the third group, the quantitative component is associated with the set, the number of which it denotes. This approach allows us to define restrictions on synonymous substitutions between phraseologisms eith a common value of "indefinitely large quantity" and to avoid errors characteristic of foreigners.

Keywords: Russian language, phraseologisms, indefinite large quantity, synonymy, contextual freedom, contextual connectedness, pragmatic approach, valence bonds.

\author{
Чжан Цзинтао \\ аспирант, Московский Педагогический Государственный \\ Университет \\ raing8890@mail.ru
}

Аннотация: В статье рассматривается проблема классификации фразеологизмов со значением 'неопределенно большое количество'; в качестве основания для классификации предлагается не структура фразеологизмов, а степень их контекстуальной свободы / связанности. Структурный подход, предложенный М.Ю. Тихоновой, по мнению автора, не позволяет увидеть лексико-семантические оттенки в значениях ФЕ, которые (оттенки) определяют валентные связи фразеологизмов. Прагматический подход, предложенный в статье, по мнению автора, особенно актуален для иностранцев. Классификация, представленная в статье, включает три группы ФЕ: контекстуально свободные, контекстуально ограниченные, контекстуально связанные. ФЕ первой группы сочетаются с существительными разных лексико-семантических разрядов и выступают в качестве синонимов по отношению к друг другу. Валентные связи ФЕ второй группы ограничены либо дополнительными компонентами значения, связанными с внутренней формой фразеологизма, либо его многозначностью, либо структурой. В значениях фразеологизмов третьей группы количественный компонент связан с множеством, количество которого он обозначает. Такой подход позволяет определить ограничения на синонимические замены между ФЕ с общим значением 'неопределенно большое количество' и избежать характерных для иностранцев ошибок.

Ключевые слова: русский язык, фразеологизмы, неопределенно большое количество, синонимия. быденное сознание, в отличие от научного, обозначая количество, дает ему субъективную оценку. Одним из способов выражения субъективнооценочного количества являются фразеологизмы со значением'малое, большое или достаточное количество'. Фразеологизмы со значением 'неопределенно большое количество' составляют довольно большую и неоднородную группу. Попытка их систематизировать была предпринята М.Ю. Тихоновой [Тихонова 1970], предложившей классифицировать фразеологизмы исходя из их структуры: словосочетания (предложно-именные наречные обороты; прилагательное + существительное; глагол + существительное; глагол + наречие), сочетания знаменательного слова с предлогом организованные как словосочетания, сочетания знаменательного слова с отрицанием, фразеологизмы-предложения. Классификация исследователя включает 9 типов:

1. до черта, до пропасти, по горло, по/под самую завязку, по уши, без меры, без счета, без кониа, за глаза и др.;

2. не счесть, не занимать, не пересчитать, нет числа, нет счета, нет отбоя и др.;

3. непочатый край, разливанное море, челый короб, чертова пропасть, чертова тьма и др.

4. дохнуть негде, плюнуть негде/некуда, девать некуда и др.;

5. беда/страх/ужас сколько, сколько душе угодно, невесть сколько и др. 
6. хоть отбавляй, хоть завались, хоть пруд пруди, хоть лопатой отгребай и др.;

7. как сельдей в бочке, как из рога изобилия, как на Маланьину свадьбу, как песка морского, как собак нерезаных, как муравьев на гнилом пне и др.

8. (денег) куры не клюют, имя (же) им легион, пушкой не прошибешь, до Москвы не перевешаешь, до смерти не сосчитаешь, яблоку негде / некуда упасть, иголку негде / некуда воткнуть, шагу негде / некуда ступить;

9. тьма тьмущая, туча тучей, полным-полно

[Тихонова 178-179]. Данная классификация, фиксируя специфику структуры фразеологизмов, не отражает, однако, с нашей точки зрения, их семантики, которая выявляется при попытке произвести синонимическую замену. При общем значении 'неопределенно большое количество' фразеологизмы, находящиеся в данной типологии в одном ряду, очень часто невозможно использовать в одной речевой ситуации:У меня дел по горло (*у меня дел без конца) или Денег за эту простую работу он получил за глаза (*Денег за эту простую работу он получил по уши) и т.д.

Мы хотели бы предложить классификацию, основанную на прагматическом подходе. Данный подход позволяет выявить как семантические оттенки фразеологизмов со значением «неопределенно большое количество», так и условия и ограничения их реализации в речи. В соответствии с предложенным подходом фразеологизмы можно разделить на три группы: контекстуально свободные, контекстуально ограниченные и контекстуально связанные. Для выявления степени контекстуальной свободы и ограниченности мы опираемся на предложенный Л.В. Щербой [Щерба 1974: 26] метод лингвистического эксперимента, в частности синонимических замен.

Следует отметить, что многие исследователи при определении фразеологической синонимии считали достаточным наличие у фразеологизмов общего значения, игнорируя смысловые оттенки, несовпадение валентности [Коваленко 1966: 67, Иванникова 1966: 90, Чернышева 1970: 81]. Однако нам более близки идеи Ю.Д. Апресяна, который считал взаимозаменяемость фразеологических единиц одним из основных принципов синонимичности. Он писал, что «фразеологические синонимы можно определить как фразеологические единицы, которые при совпадении своего стрежневого значения отличаются оттенками значений, благодаря возникающей на этой основе лингвистической связи, способны заменять друг друга в ряде строго определенных контекстов, где они употребляются в одной и той же синтаксической конструкции и сочетаются с одним и тем же лексическим окружением» [Апресян 1966: 3].

Подхода Ю.Д. Апресяна, правда, с нашей точки зре- ния, не вполне последовательно, придерживается М.Ю. Тихонова [Тихонова 1970]. С одной стороны, она отмечает, что наличие общего лексического значения и «способность сочетаться с одними и теми же словами и на этой почве заменять друг друга» является одним из признаков синонимии. А с другой - допускает необязательность совпадения всех дистрибутивных свойств, частичную сочетаемость фразеологизмов [Тихонова 1970: 196]. Отмечая, что «синонимия лингвистических единиц базируется на общности их лексических значений, а «лексическая общность различных единиц проявляется только тогда, когда существуют одинаковые условия для их реализации», М.Ю. Тихонова тем не менее помещает в синонимический ряд фразеологизмы, которые отличаются не только «по эмоционально-экспрессивным, стилистическим свойствам», но прежде всего «сочетательным возможностям»: хоть отбавляй, пушкой не прошибешь, хоть пруд пруди, яблоку негде упасть, как собак нерезаных, плюнуть негде, до черта, несть числа [Тихонова 1970: 198]. Стоит отметить, что автор рассматривает только проблему синонимии фразеологизмов, не связывая ее со своей классификацией.

Если вернуться к предложенному нами принципу, то можно сказать, что фразеологизмы первой группы употребляются в разных контекстах и во многих из них являются синонимами по отношению друг к другу (выше крыши, хоть отбавляй); фразеологизмы второй группы употребляются не во всех контекстах; использовать их в качестве синонимов других фразеологизмов со значением 'много' не всегда корректно, а часто невозможно. Это связано с однозначностью / многозначностью фразеологизмов, со комплексностью их значений, наличием дополнительных оттенков значений (например, много + избыток / лишнее, причем с разными оценками этого избытка, и т.д.), а также со структурой фразеологизмов. В результате квантификации такие фразеологизмы градуируются [Колесникова 2010; 2015]. Фразеологизмы третьей группы обозначают не просто неопределенно большое количество, а неопределенно большое количество чего-либо конкретного / кого-либо в конкретной ситуации. Контекстуально свободные фразеологизмы чаще всего могут заменять фразеологизмы двух других групп.

Рассмотрим фразеологизмы первой и второй группы, т.е. контекстуально свободные и контекстуально ограниченные. Начнем с фразеологизмов, построенных на ориентационной метафоре: выше крыши / выше головы. Сама ориентация вверх [Лакофф, Джонсон 2004: 35], выраженная наречием выше, уже, так же, как и ориентация вширь и вглубь, передает идею 'большое количество' [см. Ли 2005: 7]. А второй компонент сравнения (антропная «вершина» голова и антропоориентированная «вершина» - крыша) дублирует это значение. При этом ФЕ выше крыши более частотный, что можно объяснить, 
во-первых, семантической его перегруженностью: наличием еще двух значений ('предел возможностей' - выше головы не прыгнешь и 'размер в высоту'- сорняки выше головы), а во-вторых, возможно, и тем, что слово крыша как опредмеченная метафора обозначает более высокую границу и, следовательно, более «чисто» выражает идею большого количества. Синтаксические условия реализации фразеологизмов - предикативный (А у меня дел на сегодня выше головы (крыши)) и адъективный признак (Занят он выше головы (крыши)): утверждение о существовании квантифицируемого множества или проявлении признака [Булыгина, Шмелев 1997: 139; Колесникова 2015]. Первая конструкция - бытийные предложения: у кого что есть в каком количестве. Во втором типе реализуется грамматическая конструкция: наречие степени выше + объект сравнения в родительном падеже. В бытийных предложениях метафорически утверждается большое количество, в конструкциях второго типа - утверждается интенсивность признака, и в этой конструкции фразеологизм синонимичен очень / очень много: (ср. занят выше крыши и сделал выше крыши). Что касается лексико-синтаксических связей выше крыши, то, по-видимому, достаточно широки: возможны сочетания с абстрактными (горя выше крыши), предметными (книг выше крыши), вещественными (земли выше крыши) личными существительными (друзей выше крыши). Согласно данным НКРЯ, наиболее часто ФЕ выше крыши сочетается с именами: дела, проблемы, заботы, работа. ФЕ выше головы, очевидно, в силу многозначности, а также внутренней формы контекстуально ограничен и не во всех контекстах синонимически замены выше крыши на выше головы возможны, например, в сочетании с существительными со значением лица (дураков / учеников / друзей выше крыши ("выше головы). По свидетельству информантов, сочетания с абстрактными (горя/радости выше головы), вещественными (воды/вина выше головы), предметными (книг выше головы) существительными тоже трудно считать адекватными русскому дискурсу, т.к. в сочетании с этими именами разрушается метафора высоко-много. Согласно данным НКРЯ, ФЕ выше головы В значении 'неопределенно большое количество' сочетается со словами работы, дел, проблем. Именно в этом контексте фразеологизмы являются синонимами; валентные связи выше крыши и выше головы неодинаковы: второй фразеологизм только в сочетании с ограниченным количеством имен заменяет первый. Поэтому выше крыши мы относим к первой группе, а выше головы - ко второй.

Фразеологизм по горло, также построенный на ориентационной метафоре (обозначение некого антропного верха), имеет в своей внутренней форме идею предела (ее передает предлог по), наиболее явно реализуемую при выражении значения 'насыщения' в буквальном и фигуральном смысле фразеологизмом сыт по горло и сыт по горло твоими советами. Очевидно, это значение накладывает ограничения на сочетаемостные возможности фразеологизма. Наиболее характерные условия реализации в речи схожи с сочетаемостью выше головы + дел, работ, забот, проблем, что об ограниченной сочетаемости и синонимических возможностях фразеологизма по горло реализующего значение 'неопределенно большое количество' в сочетании с именами, обозначающими ситуацию выполнения долга.

Фразеологизм девать некуда также имеет дополнительное значение - 'избыточное, лишнее количество'. Фразеологизмы девать некуда и выше крыши взаимозаменяемы в сочетании с личными существительными (учителей девать некуда (выше крыши); с предметными и вещественными существительными замены невозможны только из-за грамматических ограничений: в сочетании с ФЕ девать некуда имя множества стоит в В.п., а в сочетании с ФЕ выше крыши в Р.п). Если говорить о сочетаемости ФЕ девать некуда, то имена множества, так же как и в случае выше крыши могут относиться к разным лексическо-грамматическим группам. Интересно отметить, что ФЕ девать некуда не сочетается с именами типа работа, проблемы и пр., что, по-видимому, обусловлено наличием компонента 'избыточное, лишнее количество'. Структура, компонент значения 'лишнее количество' ограничивают возможности синонимической замены на ФЕ выше крыши, но валентные возможности, что позволяет нам отнести его в первой группе.

Идея избыточности передается и другими фразеологизмами: хоть завались / залейся. Однако в отличие от ФЕ девать некуда, данные фразеологизмы не акцентируют отрицательной стороны избыточного количества. Напротив, избыточное здесь не является лишним, ненужным. Глаголы завались и залейся передают идеи избыточности благодаря семантике приставки за, одно из значений которой 'чрезмерность действия'. Фразеологизм хоть отбавляй, имеющий ту же грамматическую структуру, построен по иной метафорической логике: идея избыточного количества содержится в пресуппозиции. Хоть отбавляй, так же как и выше крыши, сочетается с абстрактными (времени хоть отбавляй), предметными (книг хоть отбавляй), вещественными (воды хоть отбавляй), личными (студентов хоть отбавляй) существительными. Хоть завались чаще всего употребляется с предметными существительными; реже вещественными (Лимонаду было - хоть завались. [А.В. Драбкина. Волшебные яблоки (1975)]) личными (покупателей хоть завались); из абстрактных - наиболее частотные сочетания, согласно НКРЯ, со словами работа и добро (в значении 'личное имущество'). Стоит отметить, что наиболее контекстуально свободным в этой паре является ФЕ хоть отбавляй: синонимические замены ФЕ выше крыши на ФЕ хоть отбавляй корректны практически во всех случаях. Очевидно, идея 'много' наиболее релевантно выражается через метафорическое переосмысление 
действия со значением 'отделение лишнего', в пресуппозиции значения которого - рационально действующий субъект (хоть отбавляй), чем через метафорическое переосмысление чрезмерного действия, в пресуппозиции значения которого действуют независимые от субъекта силы (хоть завались /залейся).

Фразеологизмы (хоть) пруд пруди, (хоть) косой коси, построенные по той же структурной схеме, в своей внутренней форме имеют образ, обусловленный историческими реалиями, в их основе опредмеченная ситуация бытовой жизни. Фразеологизм пруд пруди сочетается с личными, предметными, вещественными существительными (студентов / машин / каши пруд пруди); хотя при сочетаемости с существительными, обозначающими недискретную жидкую субстанцию, происходит определенный сдвиг в опредмечивании ситуации: концептуализация происходит через другой образ - заполнение большим количеством жидкости некой емкости, а не устройство запруды. С абстрактными существительными сочетается не очень активно. Сочетаемость ФЕ хоть косой коси ограничена (грибов хоть косой коси). Фразеологизмы пруд пруди, хоть отбавляй, выше крыши в сочетании с предметными, вещественными и личными существительными взаимозаменяемы.

В основе фразеологизмов вагон и маленькая тележка и воз и маленькая тележка - существительные вагон, воз, которые сами по себе выполняют функцию квантификатора. Ли Су Хен считает, что исходное значение вагон и воз, содержащее идею перевозки людей или груза, оказывает влияние на сочетаемость данных слов [Ли 2005: 109]. Однако фразеологизмы, включающие эти квантификаторы, сочетаются с личными, предметными и вещественными, абстрактными существительными и имеют высокую степень контекстуальной свободы и в конструкции у кого есть что в каком количестве могут быть заменены на ФЕ выше крыши, хоть отбавляй, пруд пруди (Нет, - улыбнулась Эля, - у меня клиентов вагон (воз) и маленькая тележка / выше крыш, хоть отбавляй, (хоть) пруд пруди). [Дарья Донцова. Микстура от косоглазия (2003)]). Фразеологизм вагон и маленькая тележка более частотный, что обусловлено выходом из употребления референта воз.

В паре фразеологизмов, образованных по одной модели нет числа и нет кониа (и краю) второй имеет большую степень контекстуальной свободы. ФЕ нет числа чаще всего используется при обозначении неопределенно большого количества ситуаций (нет числа интригам, обидам), а также лиц как участников ситуаций (нет числа последователей, голосующих, бегунов); с вещественными и абстрактными существительными данный фразеологизм не сочетается (* нет числа чаю/ любви), что объясняется наличием слова число в составе фразеологизма, сочетающегося с существительны- ми, обозначающими «дискретную субстанцию». ФЕ нет кониа (и краю) употребляется в контекстах с именами, референты которых представляют собой либо «континуальную субстанцию», либо что-то протяженное (дороге, разговору нет кониа и краю), либо многократно повторяющиеся ситуации. Внутренняя форма фразеологизма создает пространственный образ по метафорической модели шире-много (см. [Ли 2005]).

Значение 'неопределенно большое количество' фразеологизмов, образованных по одной структурной модели ужас /страх / страсть / жуть / беда сколько передается с помощью интенсификаторов в сочетании с квантифицирующим словом, не выражающим объем количества. Различия в функционировании фразеологизмов обусловлены стилистически: беда / страх сколько - устаревшие. Наиболее частотные ужас / cmpaсть сколько, менее частотный жуть сколько. Все фразеологизмы этой группы (кроме устаревших), поскольку они могут сочетаться с личными, вещественными, предметными абстрактными существительными (ужас сколько учеников, молока, платьев, неприятностей) и выступать в качестве синонимов фразеологизмов выше крыши, хоть отбавляй, хоть пруд пруди, мы относим к контекстуально свободным.

К контекстуально связанным фразеологизмам, как уже было отмечено, мы предлагаем отнести те, в значении которых количественный компонент связан с определенным множеством (предметов, лиц и пр.) и не обозначает количество другого множества: отбою нет (много людей, желающих чего-либо: просителей, женихов, клиентов и пр.), как мухи на мёд (большое количество людей, стремящихся в ажиотаже куда-либо, к комулибо), непочатый край (много дел, работы), ешь-пей не хочу, столы ломятся, как на маланьину свадьбу (много еды и напитков), куры не клюют (много денег), голова пухнет (много забот); в три горла / три глотки (много есть), набивать голову (перегружать память больщим количеством малозначащих или ненужных, бесполезных сведений), набивать живот (много есть), набивать кошелек /карман / мошну (много получить денег, обычно нечестным путем), насосаться крови (много и долго помучить, поэксплуатировать кого-либо, поиздеваться над кем-либо); насыпать / наврать с три короба (наговорить много неправдоподобного); словно / как грибы (после дождя) ('быстро, в большом количестве возникать, появляться'). Битком набито, яблоку упасть негде, как сельдей в бочке, плюнуть некуда, (шагу) ступить негде /некуда имеют значение 'большое количество людей' или 'большая плотность скопившихся в одном месте людей.' Все эти фразеологизмы контекстуально связаны и, соответственно, ограничены в своих синонимических возможностях.

Таким образом, фразеологизмы со значением 'не- 
определенно большое количество' можно представить в виде трех групп: контекстуально свободные, сочетающиеся с существительными, относящиеся к разным лексико-семантическим разрядам и обладающие большим синонимическим потенциалом (выше крыши, девать некуда, хоть отбавляй, ужас сколько, вагон и маленькая тележка); контекстуально и синонимически ограничен- ные (нет числа, нет конца и краю, хоть залейся и др.) и контекстуально связанные. Нам представляется, что прагматический подход к классификации фразеологизмов с точки зрения их валентных связей и синонимических возможностей, актуален для иностранцев, поскольку дает возможность обозначить «зону запрета» и избежать характерных для иностранцев ошибок.

\section{ЛИТЕРАТУРА}

1. Апресян, Ю.Д. Фразеологические синонимы типа «глагол + существительное» В современном английском языке.: автореф. дис. . канд.филол.наук / Юрий Апресян. - М., 1956. - 15 с.

2. Булыгина, Т.В. Языковая концептуализация мира (на материале русской грамматики) / Т.В. Булыгина, А.Д. Шмелев. - М.: Языки русской культуры, 1997. - 574 с.

3. Иванникова Е.А. Синонимические отношения между фразеологическими единицами и словами // Очерки по синонимике современного русского литературного языка. М. - Л., 1966. - 153 с.

4. Колесникова С.М. Градуирование и квантификация в современном русском языке // Studia Slavica, Hang, 60/1 (2015). - Akadémiai Kiadó Budapest, 2015. - C. $55-64$.

5. Колесникова С.М. Функционально-семантическая категория градуальности в современном русском языке: Учебное пособие. - М.: Высшая школа, 2010. - 279 с.

6. Коваленко Т. И. К вопросу о вариантности и синонимах глагольных фразеологизмов в современном русском языке // Науч. зап. МГПИ. Т. 160. Русский язык. Вып. 2. М., 1966. С. 65-72;

7. Лакофф Д., Джонсон М., Метафоры, которыми мы живем. - М.: Едиториал УРСС, 2004.

8. Ли Су Хен. Когнитивный анализ русских конструкций с именными квантификаторами : автореферат дис. ... кандидата филологических наук : 10.02.01, 10.02.20 / Рос. гос. гуманитар. ун-т (РГГУ). - Москва, 2005. - 25 с.

9. Тихонова, М. Ю. Лексико-фразеологическая микросистема «много» в современном русском языке: автореф. дис. ... канд. филол. наук / М. Ю. Тихонова. - Самарканд, 1971. - 18 с. 230

10. Чернышева И.И. Фразеология современного немецкого языка. М.: Высшая школа, 1970. - С. 81.

11. Словарь-справочник лингвистических терминов. // Розенталь Д.Э., Теленкова М.А. [Электронный ресурс]. - URL: https://dic.academic.ru/dic.nsf/lingvistic (дата обращения: 30.11 .2019 )

12. Толковый словарь русского языка / Под ред. Д.Н. Ушакова.- [Электронный ресурс] - URL: https://dic.academic.ru/dic.nsf/ushakov/834310 (дата 06ращения: 01.12.2019)

13. Фразеологический словарь русского литературного языка : около 13000 фразеологических единиц / А.И. Федоров. - 3-е изд., испр. - Москва: АСТ : Астрель, 2008.

14. Щерба Л.В. 0 трояком аспекте языковых явлений и об эксперименте в языкознании // Языковая система и речевая деятельность. - Л., 1974. - С. $24-39$ - [Электронный ресурc] - URL: http://philology.ru/linguistics1/shcherba-74a.htm

15. Национальный корпус русского языка. - [Электронный ресурс] - URL: http://ruscorpora.ru/old/index.html (дата обращения: 10.11.2019)

(с) Чжан Цзинтао (raing8890@mail.ru).

Журнал «Современная наука: актуальные проблемы теории и практики» 